\title{
Pricing and demand management of air tickets using a multiplicative newsvendor model
}

\author{
Doraid Dalalah $^{1,2} \cdot$ Mohammad Khasawneh $^{1} \cdot$ Sharafuddin Khan ${ }^{1}$
}

Received: 15 September 2021 / Accepted: 11 November 2021 / Published online: 23 November 2021

(c) The Author(s), under exclusive licence to Springer Nature Limited 2021

\begin{abstract}
As each day passes by, the number of flights expands and the need for travel quality services continues to grow. In consequence, for an airline to remain in market, better revenue management is required such that the same quality of service is offered at reasonable prices. Since cost cut plans may be disrupted by the need to uphold quality of service, demand and sales management plans can be one of the best techniques for the management of revenues in airlines. To excel in providing safe and most comfortable flights at sensible prices, airlines should objectively employ advanced techniques to reduce the costs and maximize the earnings, which can be achieved via seat allocation and pricing of different classes. Toward achieving such an objective, in this work, we seek to find the best prices of two different seating classes. Here, two economy classes are considered for pricing and quantification, where the optimal number of seats of each class is expressed in a closed form and the prices that will maximize the size of sales are computed accordingly. Using a multiplicative demand model and the newsvendor approach, the best discount rates and the optimal number of seats could be found. The proposed model is tested using real flight data; it was found that for a normally distributed demand, the sales can be increased by allocating the right number of seats for both the regular and the discount seats. Not only the prices can maximize the sales, specific discount ratios were found to improve the sales too. The model can assist revenue managers to increase the sales via the right selection of the number of economy seats and prices.
\end{abstract}

Keywords Revenue $\cdot$ Pricing $\cdot$ Flight $\cdot$ Ticket $\cdot$ Sales $\cdot$ Newsvendor

\section{Introduction}

In revenue management of the air industry, the type of offerings and pricing of air tickets are considered as key aspects for the success of air carriers. Managing classes, seat allocation and pricing of flights can be a challenging task. Although ticketing business falls in the category of perishable stock, the ticket inventory unlike others, has its own characteristics. Airline tickets have dynamic prices, with

Doraid Dalalah

ddalalah@sharjah.ac.ae

Mohammad Khasawneh

mkhasawneh@sharjah.ac.ae

Sharafuddin Khan

skhan@sharjah.ac.ae

1 Industrial Engineering and Engineering Management, College of Engineering, University of Sharjah, Sharjah, UAE

2 Industrial Engineering, Jordan University of Science and Technology, Irbid, Jordan a limited useful life, beginning from the day the flight is scheduled until plane take-off. For this reason, it is important to excel at classifying seats and pricing tickets to maximize profit, and increase seat utilization on every flight.

In airlines, a typical decision problem faced by the revenue managers is seat classification and pricing. While cost cut is considered as an efficient approach to increase profit, cost cuts significantly affect the quality of service. Different tactics such as Airbnb, while deemed attractive to certain categories of travelers, cost cuts can touch a limit beyond which a significant drop in quality of service can be noticed. Therefore, to achieve satisfactory earnings, airlines work to increase the sales and avoid/eliminate lost sales or traveling with empty seats, which significantly reduces the profit. One common revenue maximization policy is the non-refundable tickets, which are not so attractive to travelers. A nonrefund policy although may come with lower ticket prices, it is not attractive to a good deal of travelers. Overbooking, as another review management approach, puts high bets on flight no-shows. In fact, the risk involved in overbooking 
policies as employed in some airlines, brings other penalties including compensations, refunds and loss of customer trust once those customers encounter boarding denial due to fully booked flights.

Bearing in mind that such revenue management policies may raise customer dissatisfaction, it is important to explore the best approaches that maintain a good profit margin without having to sacrifice loyalty and customer satisfaction.

In this article, we propose a model to increase the profit and maximize the sales via a novel seat allocation and ticket pricing analysis. Here, two seat classes are considered, namely, regular fare and discounted fare seats. The goal of this study is to identify the number of seats that should be offered at a regular price and that offered at a discount price for a specific flight leg. In addition to identifying the number of seats of each class, the proposed analysis will also help find the best discount ratio that will increase the expected sales, thereby, maximizing the profit.

According to the above, the airline decision problem comes in twofold: first, for a scheduled flight of specific capacity on a specific day, the airlines will offer two prices; the discount price which is offered for a specific number of seats. A seat at a discount price can be sold anytime after the flight is scheduled up until all seats are sold or once the timeframe of discount sale is over. Once the discounted fare seats are sold, the remaining seats will be sold at the regular price until check in. Unsold seats in this case are flown empty. According to this, early bird customers can buy their tickets at a discounted price, while late comers will have to buy the ticket at a regular price. Second, by offering two airfares per flight, it is important to identify the fares as prices significantly affect the demand for tickets. In this work, we will also identify the prices that will increase the expected sales. For this purpose, we employ a multiplicative demand model that shows the tradeoff between the discounted price and the resulting demand.

\section{Motivation}

Airline industry offers a vital type of service. As the demand for flights increases day by day, the expansion and growth of such a business becomes important to maintain credibility, quality of service, competitiveness and to remain in market. The development in this business should focus on reducing costs, increasing efficiency and utilization, yet retaining customers by assuring satisfaction. Over decades of experience and research in the airline business, cost cuts almost have come to a cliff that may touch the quality of provided service, hence, from the airline's perspective, revenue management can be addressed by creative offers, packages, prices, deals, etc. Pricing and seat offering are one of those management tools addressed in this article without sacrificing the customers' comfort and satisfaction.
Specifically, the objectives of this article that should contribute to the body of existing literature include:

- Highlight the main characteristics that affect the airlines' performance.

- Propose a multiplicative demand management model.

- Specify the best combination of seat numbers of different classes and the offered prices that will maximize the sales and reduce the opportunity losses.

- Utilize the newsvendor approach to allocate the seats.

- Perform a numerical analysis to identify the best discount ratio that will increase the sales.

\section{Literature review}

A massive body of literature exists on different seat allocation and revenue management problems. The introduction to this literature was first initiated by Whitin (1955) and Karlin and Carr (1962) in the fifties and sixties of the last century. However, these articles provided a broader perspective on newsvendor problem of single-product price setting. Flight seat allocation and pricing was later introduced as part of airline yield management problems with a broader view on revenue management in general (Belobaba 1987). Airline yield management problems with focus on pricing models have been recently reviewed by Bitran and Caldentey (2003), Mookherjee and Friesz (2008), Cizaire and Belobaba (2013), and Zhao et al. (2017). Cizaire and Belobaba (2013) were among the first to analyze seat allocation and airfare pricing as a joint optimization problem since most preceding research considered the two issues separately. Seat allocation and airfare pricing were further investigated as a joint concept in Zhao et al. (2017) who addressed the problem in a duopoly game theory model with linear additive pricedemand functions and bivariate normally distributed joint demand.

Pertiwi et al. (2015) introduced a quantity-based yield management approach for its importance in airline companies since flights have a fixed number of seats and hence there has to be an optimal customer mix through seat allocation to maximize the revenue. According to Liu et al. (2016), the allocation of flight seats according to seat class is an effective and doable revenue management approach.

Seat allocation was reviewed separately in Lan et al. (2015), who investigated the heavy reliance of seat allocation on demand forecasting. Seat allocation was classified as an inaccurate and non-optimal, due to non-stationary demand and the oversimplification of demand assumptions. To overcome the demand assumptions, Ko (2019) came with a study that considers a set of factors in forecasting the demand for flight seats based on historical data. Such factors include the economic situation, special events, holidays, and 
other interacting factors that can beget optimal seat allocation for any flight leg when techniques like the seat inventory control method is implemented.

Wang (2016) and Chen and Farias (2018) have reviewed flight ticket pricing and revenue maximization models to optimize the customer experience and ticket sales time. Wang (2016) has also reviewed the concept of dynamic alteration of ticket prices in response to several influencing factors including current demand, consumer behavior, ticket prices offered by competitors in the industry, and other internal and external factors. These factors were further investigated by Martínez et al. (2017), who concluded that competition is one of the main elements with a significant effect on price dispersion. Martínez et al. (2017) has also indicated that customer and flight seat classifications (economy, leisure, and business classes) are other important contributing factors to both price dispersion and revenue maximization regardless of the high incurred costs at leisure and business class. In a related work, Dalalah et al. (2020) has also discussed factors affecting ticket pricing and the supply-demand equilibrium in terms of its impact on revenue. According to Tesfay (2016), the load factor is controlled by six main drivers; those are the demand growth, pricing and discount fares, the traffic mix, strictness of the payment policy, commercial success, and accuracy of demand forecasts.

Aside from revenue maximization, cost reduction is a very important profit maximization factor that must be addressed by breaking down the airline non-fixed cost into operating and non-operating costs (Alves and Caetano 2016). The classification of costs can help airlines prioritize the costs constituents, which if reduced, will lead to a significant reduction in the flight seat cost. It is important to focus on direct operating costs over indirect costs since indirect costs are not specifically related to a particular flight and are not directly reliant on aircraft operations. However, the traditional relationship between revenue and cost can be disrupted by some external and internal factors like seasonality; which is one of the most common demand phenomena. According to Merkert and Webber (2018), seasonality is demonstrated as a pattern that is observed in the demand for flight seats in the airline industry. Seasonality and its effects are investigated in the article by developing elasticity model to benchmark airlines strategic performance. On the other hand, Alrawabdeh (2021) argues that variability is a recurring phenomenon, and therefore, seasonality in customer demand should be studied and forecasted.

nother important external factor that recently affected seat allocation and pricing is Covid-19, which had a significant impact on the airline industry as a whole. The airline industry has undergone major changes and experienced a sharp decline owed to further restrictions on travel and transportation. Sakkakom and Kotcharin (2020) addressed the impacts of COVID-19 on the global airline industry by studying 52 recorded airline organizations around the world. The outcomes of the study showed that airline stock profits decreased more extensively than the market profits after three main announcements were made about Covid-19, including the announcements of the World Health Organization. The effect of the pandemic went to the extent that American Airlines reduced the global 2020 summer flights by $60 \%$ because of coronavirus and government travel restrictions. According to literature studies, COVID-19 pandemic has also affected the load factor as the case of Delta airlines which experienced significantly low load factors. The maximum load factor for Delta during the pandemic was $60 \%$ to keep social distancing onboard. Although the travel restrictions have been later softened a bit, the load factor was just over $40 \%$ in June 2020. The high variability and unpredictability brought along with the pandemic made it harder for any airline to forecast the load factor.

Bearing in mind the above discussion, in this research, a pricing model is introduced to maximize the sales using a novel multiplicative demand approach, which is employed to serve a variant of the newsvendor problem for seat allocation. Both the prices and seat quantities will be identified such that the expected sales are maximized.

\section{Flight scenario}

Airlines are always confronting uncertainties in demand for tickets, a situation that brings about challenges in assigning the seats to different classes and in identifying the associated seat/ticket prices. Many techniques have been used for allocating seats according to the fare. In our literature, it was noticed that optimization tools and techniques were used, yet limited studies if any, have adopted the newsvendor model to address seat allocation according to prices.

To better understand the undelaying assumptions of our model, first, we begin by the description of the scenario being tackled here. For a specific flight to a certain destination, once the flight is scheduled, two seat prices are offered but at different time frames. First, the discounted price $p_{\mathrm{d}}$ which is offered right after the flight is scheduled until all seats are sold. Here, we assume that the discounted price is sufficiently attractive to assure booking of all discounted seats. Once the discounted seats are sold, the remaining/ allocated seats are offered at a full fare price (regular price) $p_{\mathrm{r}}$, which is, in essence, higher than the discounted price $p_{\mathrm{d}}$. With these settings, travelers are encouraged to book as early as possible to avoid discounted seats run out, alternatively, they will have to book at a regular but more expensive price. Given the prices above, the discount ratio is expressed as: 
$R=\frac{P_{\mathrm{r}}-P_{\mathrm{d}}}{P_{\mathrm{r}}}$

To this end, the scenario seems to be common in most airlines; however, the decision of how many seats to reserve for the regular price and at what sale price remains an intricate task which will be addressed shortly in this research.

\section{The multiplicative demand model}

Suppliers and buyers have different perceptions of prices. From the suppliers' perspective, it is more purposely required to stream revenues, which is done by increasing the prices and lowering the costs. On the other hand, buyers seek to pay less while getting the same quality of service. However, a compromise between the traveler and airline needs can be achieved to certain extents by managing the demand via different offers, loyalty plans, and discounts.

Airline tickets are considered to have an elastic demand. Whenever there is a decline in prices (discounts), people will be more willing to buy tickets than when the tickets are offered at their regular prices. This characteristic in airline ticketing makes decisions regarding pricing and seat allocation more challenging. From this point, however, one could turn this challenge into an opportunity via implementing discount ratio analysis as the case in this study.

To start with, different data were collected from Air Arabia, an international air carrier in the Middle East which has destinations to more than 50 cities all over the world. By considering one specific destination, namely, flight G9105 from Sharjah to Bahrain, the discount ratio of two offered prices ( $\left.\frac{\text { high-low }}{\text { high }}\right)$ at different timeframes versus the observed sales is shown in Fig. 1; here, the sales were recorded end of each priced timeframe and the percentage between the prices was computed accordingly for an Airbus A320 flight G9105 of Air Arabia.

The figure shows that low ratios result in higher sales on discounted seats and less sales on higher fare. Not only the

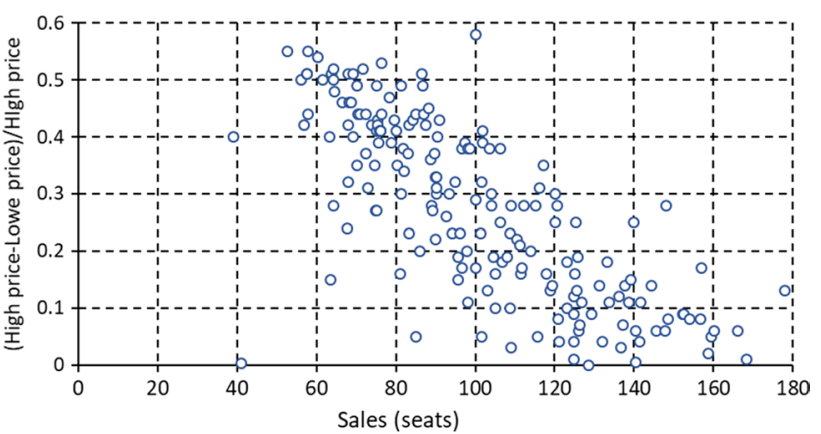

Fig. 1 Two price percentage for one flight (G9105) vs. sales price, but the variation also seems to increase at low ratios. While low discount ratios yield less sales of discounted seats and higher sales for the regular seats with a wider range of variation.

Such a behavior leads to the concept of multiplicative demand, were both the mean and variation of the demand vary according to the offered prices. In this context, there will be two extreme cases for the discount ratio. First, when the discount ratio equals $0 \%$ (i.e., no discount, $p_{\mathrm{d}}=p_{\mathrm{r}}$ ) and the other hypothetical extreme when the discount ratio equals $100 \%$ (i.e., a free seat, $p_{\mathrm{d}}=0$ ). Having a $0 \%$ discount ratio will make no difference to travelers since there will be only one price. In contrast, offering a $100 \%$ discount will encourage travelers not to buy the tickets at the regular price. To illustrate, consider the sketch in Fig. 2, which shows the average demand and the standard deviation vs. the discount ratio. At a $100 \%$ discount, the mean and standard deviation of the regular price are both zeros, which in reality makes sense knowing that none of the travelers will buy at a regular (high) price when she/he could get a free ticket. On the other extreme, by offering a zero discount, the demand for regular price will not be affected and the variation in demand will be the same since only one price is offered here i.e., $p_{\mathrm{d}}=$ $p_{\mathrm{r}}$. The pattern between the two extremes can be modeled in linear relationship following many literature studies on multiplicative demand analysis (Nicholas and Dada 1999). By exploring the sketch in Fig. 2, at a discount ratio of $40 \%$ for instance, the demand will be $\operatorname{Norm}(30,15)$. Similarly, it will be $\operatorname{Norm}(50,20)$ at a zero discount, which is considered as reference point in multiplicative demand model.

With this in mind, the mean and standard deviation at a specific discount ratio $R$ can be obtained using the following formulas:

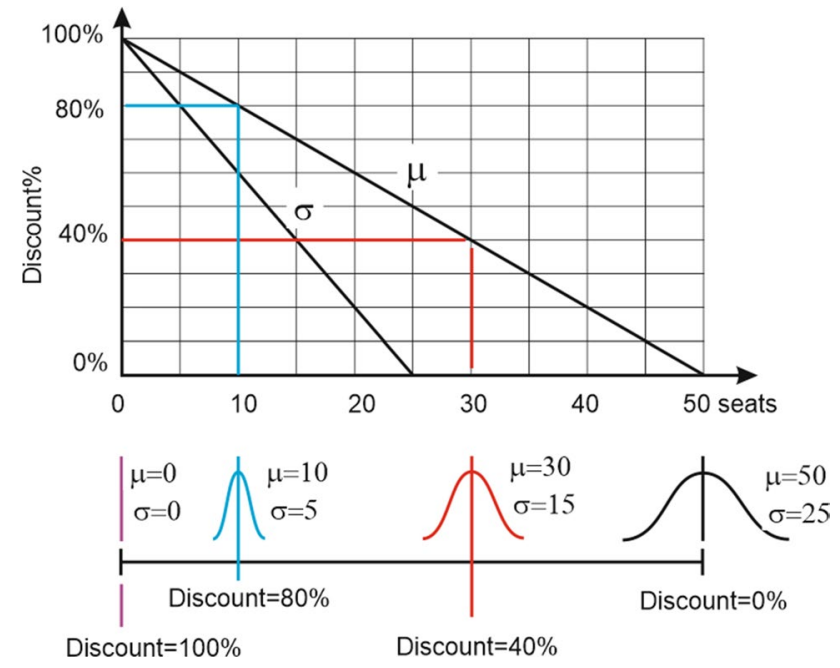

Fig. 2 Relationship between discount ratio, standard deviation, and the mean 
$\left.\begin{array}{l}\mu=\mu_{1}(1-R) \\ \sigma=\sigma_{1}(1-R)\end{array}\right\}$

where $\mu_{1}$ and $\sigma_{1}$ are the estimated mean and standard deviation of the demand for seats at the regular price. Clearly, the mean and the standard deviation of the number of seats offered at a regular price are inversely proportional to the discount ratio. Thus, when the discount ratio increases, the mean and standard deviation decrease as shown in Fig. 2. However, by increasing the discount, most of the sales will gradually go for the discounted price.

The highest standard deviation would be found at a $0 \%$ discount ratio. A higher standard deviation indicates higher risk for airlines, which generally leads to higher expected lost sales. As previously mentioned, the discount ratio will simultaneously affect both the mean and standard deviation.

\section{Optimal seat allocation}

Given the settings above, the twofold objective of this study is to determine the number of seats out of the total available capacity in an economy class that is reserved at the regular price and also at a discounted price. The second fold of our objective is to determine the best discount ratio that maximizes the sales. By assumption and to better mimic reality, all seats offered at the discounted price which are given by $(C-Q)$ will be sold, on the other side, sales at the regular price which is given by $(Q)$ will follow some demand distribution, where $C$ is the flight capacity of the class under

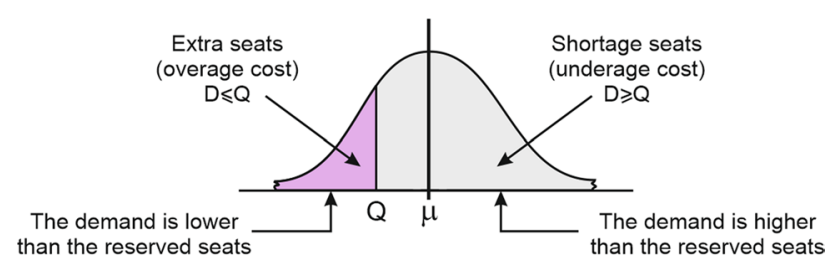

Fig. 3 The demand distribution of the regular fare consideration. Suppose that the demand for regular seats follows a normally distributed pattern e.g., $\operatorname{Norm}(\mu, \sigma)$, for this scenario, there will be a probability that the demand goes lower/higher than $Q$. Each possibility here results in a different revenue.

In the most common case, there are two prices that are considered in economy flights, namely; regular and discounted prices. Note that, if all seats are offered at a regular price, the sales may not be that high and this will yield an underage cost, which is related as an opportunity loss for the company. Similarly, if all seats are offered at a discounted price, the revenue will be lower, and there will be another type of losses. Offerings of seats at a regular price under the assumption of stochastic demand can be formulated by a newsvendor problem as shown in Fig. 3.

A question might arise, why airlines offer a discounted price if they get more earnings under the regular price? There are different reasons to offer seats at a discounted price. Evidently, one fixed price does not necessarily promote the sales. Moreover, an in advance purchase at lower prices makes flight planning much easier via offering the lowest prices to those buying with the most advance notice. While we assume two price categories in this research, in reality, seats can be offered in more than two. Airlines can sell up to 10 different fares even inside the economy class, depending on advance purchase, duration of stay, and availability. Figure 4 shows seats of two price categories for an economy class.

The newsvendor model is frequently used to manage the inventory of perishable products or services which are characterized by their short life and one time sale opening. The analysis of the newsvendor model requires two cost components: underage cost $\left(c_{\mathrm{u}}\right)$ and overage cost $\left(c_{\mathrm{o}}\right)$. Underage cost is the incurred cost due to low offerings when the demand is high, this happens whenever the demand is higher than the number of seats allocated to the regular price. In our case, low offerings of regular seats before a high demand is realized results in an opportunity loss that is equivalent to the difference between the two low and high prices. This is

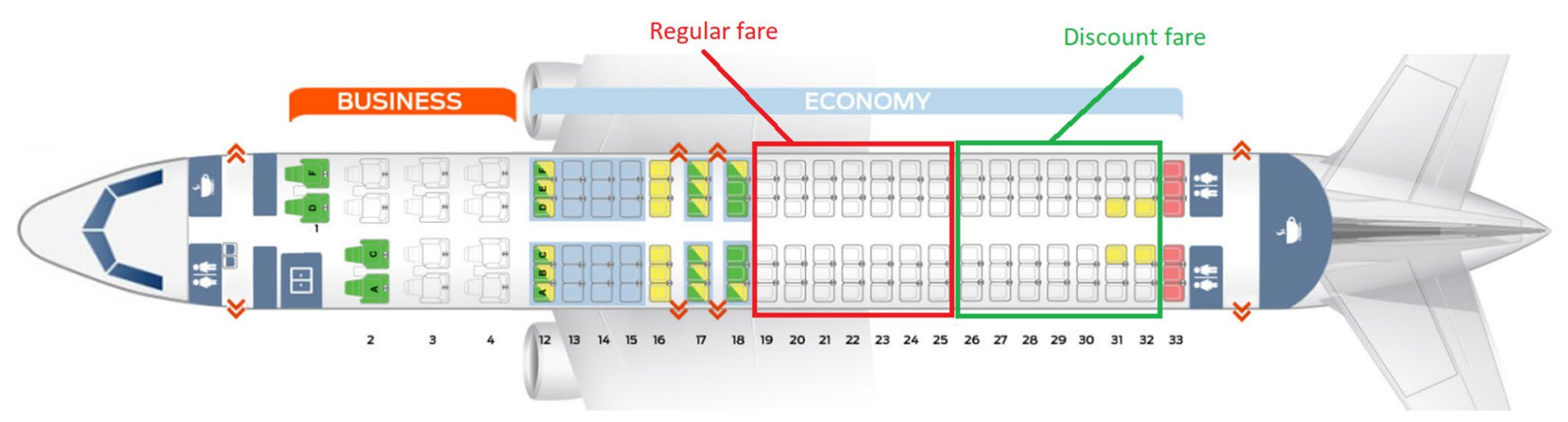

Fig. 4 Seat Prices according to the configuration of Airbus 320 
because the seats that are not offered at a regular price are sold at the discounted price when they could have been sold at the regular price, therefore,

$c_{\mathrm{u}}=p_{\mathrm{r}}-p_{\mathrm{d}}$,

and the shortage in seats can be found as follows:

Quantity short $=\left\{\begin{array}{cl}D-Q & \text { if } D \geq Q \\ 0 & \text { if } D<Q\end{array}\right.$

where $Q$ is the quantity (a decision variable), and $D$ is the demand for regular seats (a random variable). On contrast, the overage in offered seats is a situation when the demand is lower than the reserved seats of the regular price, meaning that, more seats are offered than demanded. Therefore, a quantity of $Q-D$ could have been sold at a discounted price, but they were not. This results in an overage cost $c_{\mathrm{o}}$, therefore, the overage cost is expressed by:

$c_{\mathrm{o}}=p_{\mathrm{d}}$,

and the quantity of seats left is given by:

Quantity left $=\left\{\begin{array}{cc}Q-D & \text { if } Q D \\ 0 & \text { if } Q<D\end{array}\right.$

The goal of the newsvendor model is to minimize the underage and overage costs by identifying the optimal number of seats reserved at a regular price. Following the typical modeling of the newsvendor problem, the cost function $G(D$, $Q)$ can be expressed as:

$G(D, Q)=C_{\mathrm{o}} \operatorname{Max}(0, Q-D)+C_{\mathrm{u}} \operatorname{Max}(0, D-Q)$

Define the expected value of $G(D, Q)$ by $G(Q)=E(G(D, Q))$ and let $f(x)$ be the distribution of the demand for regular seats, the expected value of $G(D, Q)$ will be:
$F\left(Q^{*}\right)=\frac{C_{\mathrm{u}}}{C_{\mathrm{o}}+C_{\mathrm{u}}}$

Next, substitute the values of $c_{\mathrm{u}}=p_{\mathrm{r}}-p_{\mathrm{d}}$ and $c_{\mathrm{o}}=p_{\mathrm{d}}$ in the critical ratio formula to get the following:

$F\left(Q^{*}\right)=\frac{p_{\mathrm{r}}-p_{\mathrm{d}}}{p_{\mathrm{r}}}=R$

For different applications of different settings, the interesting formula presented in (8) can be found in different forms in literature which is deemed as one of the renowned forms in revenue management studies. In fact, it can be applied to all kinds of continuous and discrete demand distributions and not necessarily the normal distribution.

To demonstrate, consider a flight heading to a specific destination that consists of 300 economy class seats, the optimal number of seats that should be reserved to the economy class is 183 when the demand for the regular fare is $\operatorname{Norm}(200,20)$ and the discount ratio is $20 \%$ which results from the equality $\boldsymbol{F}\left(\boldsymbol{Q}^{*}\right)=0.2$.

\section{Expected sales and expected lost sales}

Other interesting measures that provide better insights to our decision problem is the expectations of different quantities such as the sales and lost sales. The expected sales are simply the average demand less the expected lost sale, that is:

Expected sale $=\mu-$ expected lost sale

The expected lost sale is the expected value of $D-Q$ only when $D>Q$ that is given by $\int_{Q}^{\infty}(D-Q) f(D) d D$, which upon solving will result in:

$G(Q)=C_{\mathrm{o}} \int_{0}^{\infty} \max (0, Q-x) f(x) \mathrm{d} x+C_{\mathrm{u}} \int_{Q}^{\infty} \max (0, x-Q) f(x) \mathrm{d} x=C_{\mathrm{o}} \int_{0}^{\infty}(Q-x) f(x) \mathrm{d} x+C_{\mathrm{u}} \int_{Q}^{\infty}(x-Q) f(x) \mathrm{d} x$

Now, to specify the quantity $Q$ that will minimize the expected costs $G(Q)$, Leibniz's rule of integration is used to get the following:

$\frac{\mathrm{d} G(Q)}{\mathrm{d} Q}=C_{\mathrm{o}} \int_{0}^{Q} 1 f(x) \mathrm{d} x+C_{\mathrm{u}} \int_{Q}^{\infty}(-1) f(x) \mathrm{d} x=C_{\mathrm{o}} F(Q)-C_{\mathrm{u}}(1-F(Q))$

where $F(Q)$ is the cumulative distribution of the demand probability density function $f(x)$. Toward the optimal solution $Q^{*}$, we make the first derivative of $G(Q)$ equal to zero, which ultimately results in the so-called critical ratio as shown in (8):
Expected lost sale $=\sigma L(z)$

where, $L(z)=\varphi(z)-z(1-\Phi(z))$ is the well-known loss function of the normal distribution, $\varphi(z)$ is the density function of the standard normal distribution and $\Phi(z)$ is the cumulative function of the standard normal distribution. Following the same analysis, the fill rate is given by:

Fill rate $=\frac{\text { Expected sales }}{\mu}$

For instance, consider an A320 flight that has 150 seats. Let the regular seat price $p_{\mathrm{r}}=\$ 500$, the discounted price $p_{\mathrm{d}}=\$ 300$, and the demand for regular seats follow 
$\operatorname{Norm}(100,20)$. To find the expected sales, we have to find the underage and the overage costs from ( 2 and 3 ), that is: $c_{\mathrm{u}}=500-300=\$ 200$ and $c_{\mathrm{o}}=\$ 300$. Thus, the critical value will be $F\left(Q^{*}\right)=\frac{200}{200+300}=0.4$. Using the inverse function of the normal distribution to find $Q$, we get $Q=95$ seats for regular and 55 for discounted seats. For this example $\mu=100, \sigma=20$, therefore, $z=-0.25$ and the e x p c t e d $\quad$ o s t $\quad \mathrm{s} \mathrm{a} 1 \mathrm{e}=\sigma L(-0.25)$ $=20 \times[\varphi(-0.25)+0.25(1-\Phi(-0.25))]=10.7 \approx 11$ seats. This yields an expected sale of $\mu-10.73 \approx 89$ seats of the regular fare.

Recall the multiplicative demand model, which shows that for every discount ratio, there is a new demand distribution regardless of the prices. Each demand distribution results in a new optimal number of seat and hence new expected sales as shown in Fig. 5.

With this in mind, one can iterate across different discount ratios while monitoring the expected sales. The discount ratio that demonstrates the highest sales is a one that airlines sales managers are looking for. Of note, the values of expected sales vs. the discount ratio will always demonstrate a concave pattern. In the next section,

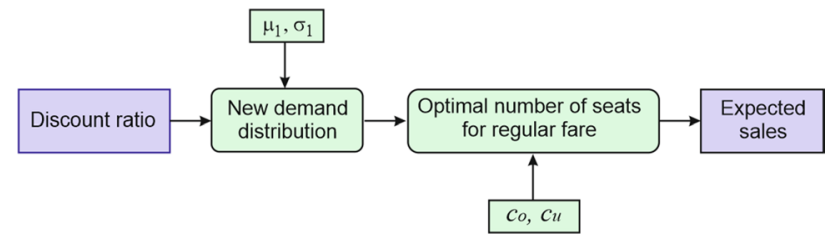

Fig. 5 Computational steps toward the expected sales we demonstrate how to find the best discount ratio that maximizes the sales for selected flights from a real airline carrier.

\section{Experimental results}

To validate the proposed analysis, we consider Air Arabia from UAE, a renowned international airline carrier in the Middle East with more than 50 international destinations all over the world.

In our experiments, all flights we are analyzing fly from Sharjah (Sharjah international airport) to Manama (Bahrain international airport). The flights in this route have three codes: G9101, G9103, and G9105. For G9105, the majority of flights are operated by Airbus A320 with 168 economy seats. The economy class has two fares, the regular price, and the discounted one. A one-way non-stop flight for one adult from Sharjah to Bahrain (at a regular price) costs $p_{\mathrm{r}}=1023 \mathrm{AED}$, while the discounted price is $p_{\mathrm{d}}=768$ AED. The prices are considered for the period of March $302020 \pm 20$ days. The prices are shown in Fig. 6, which is sourced from Air Arabia reservation website.

The load factor of the selected flight is shown in Fig. 7, which seems to be steady over a long period of time.

To find the mean and standard deviation of G9105, data were collected for 428 daily flights operated to the same destination for the period of 1/Jan/2019 to 14/March/2020. The estimated mean and standard deviation are 139.44 and 6.8 , respectively. Regardless, a normality assumption still needs a normality test, which is depicted in Figs. 8 and 9 for the same data. Note that the $p$ value $(>0.05)$ does not provide enough evidence to reject the normality assumption.

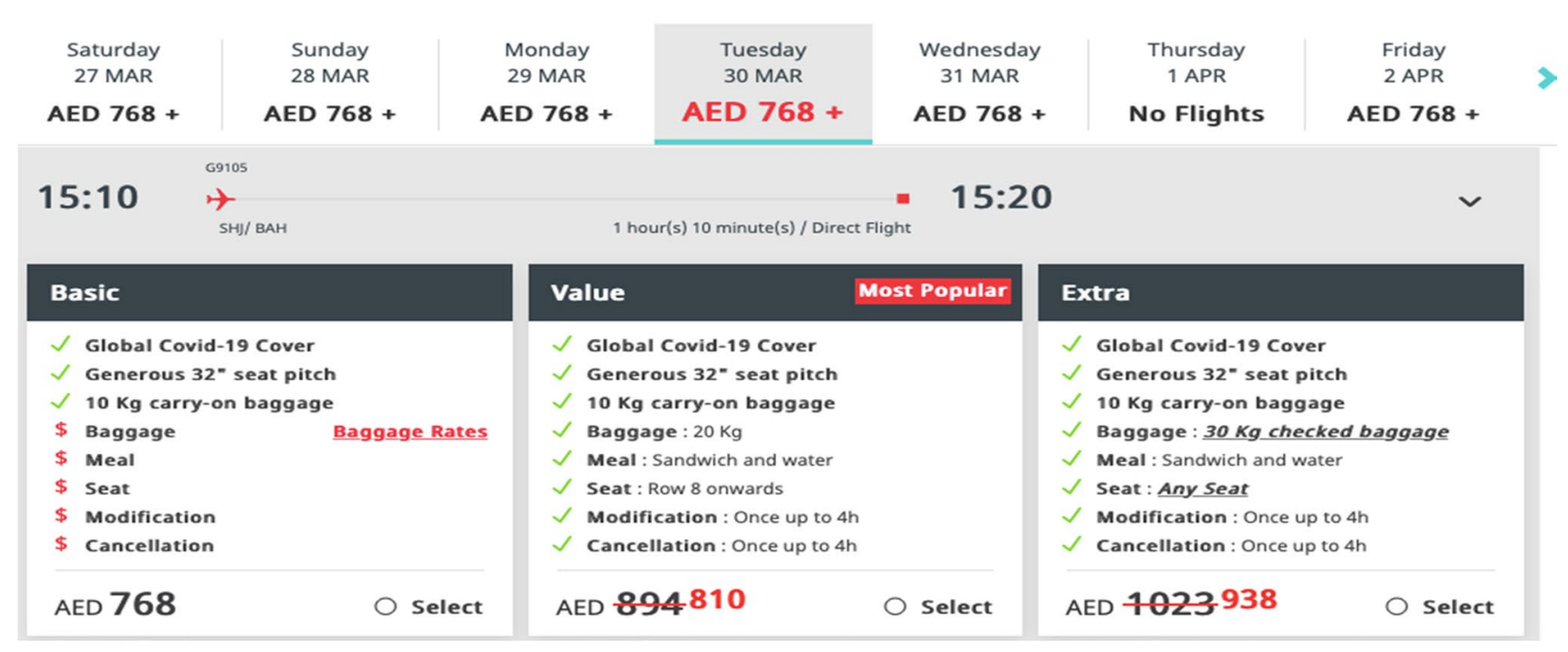

Fig. 6 Ticket prices, source: Air Arabia reservation website 
Fig. 7 The yearly load factor of Air Arabia for G9105

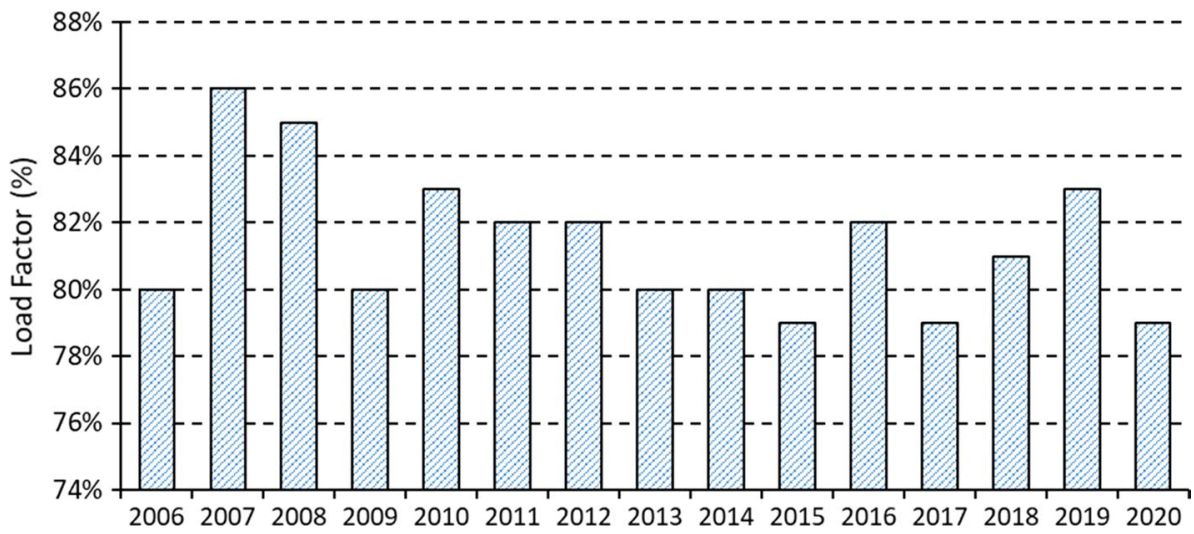

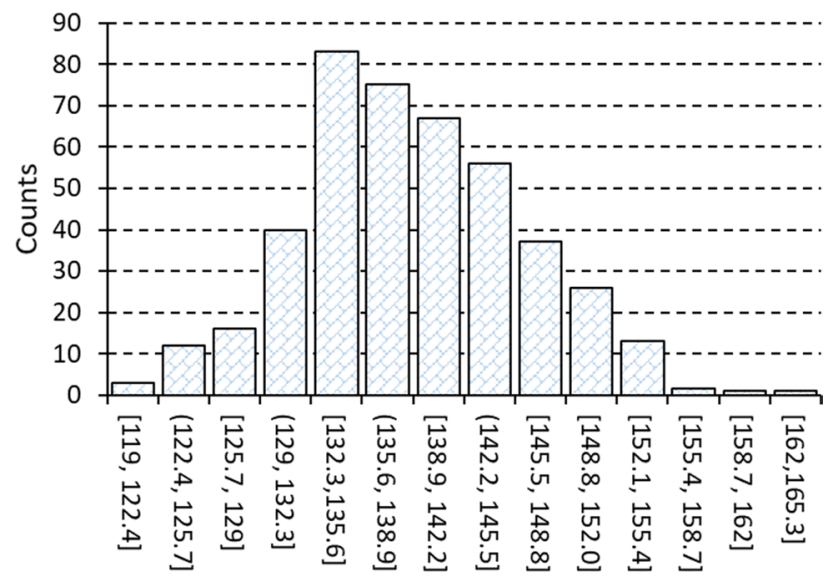

Fig. 8 A histogram of the number of passengers for G9105 using 14 bins
For this flight, first, we examine the effect of changing the discounted price on the optimal number of seats reserved for the regular fare by keeping a constant regular price of 1023AED. To do so, for every new discounted price, we find the discount ratio, then compute the new mean and standard deviation, find the optimal number of seats, and lastly find the expected sales. Table 1 shows a sample of the results at three different discounted prices.

Table 1 shows that for the same regular price, more discounts require allocating more seats for the regular price and less for the discounted price. If no discount is offered, the optimal number of seats that should be allocated for the regular price is 118 seats. We can conclude an inverse relationship between the discounted price and the optimal number of seats reserved for regular fare.
Fig. 9 Normality test for the collected data using Minitab
Probability Plot of Number of seats (regular fare) Normal $-95 \% \mathrm{Cl}$

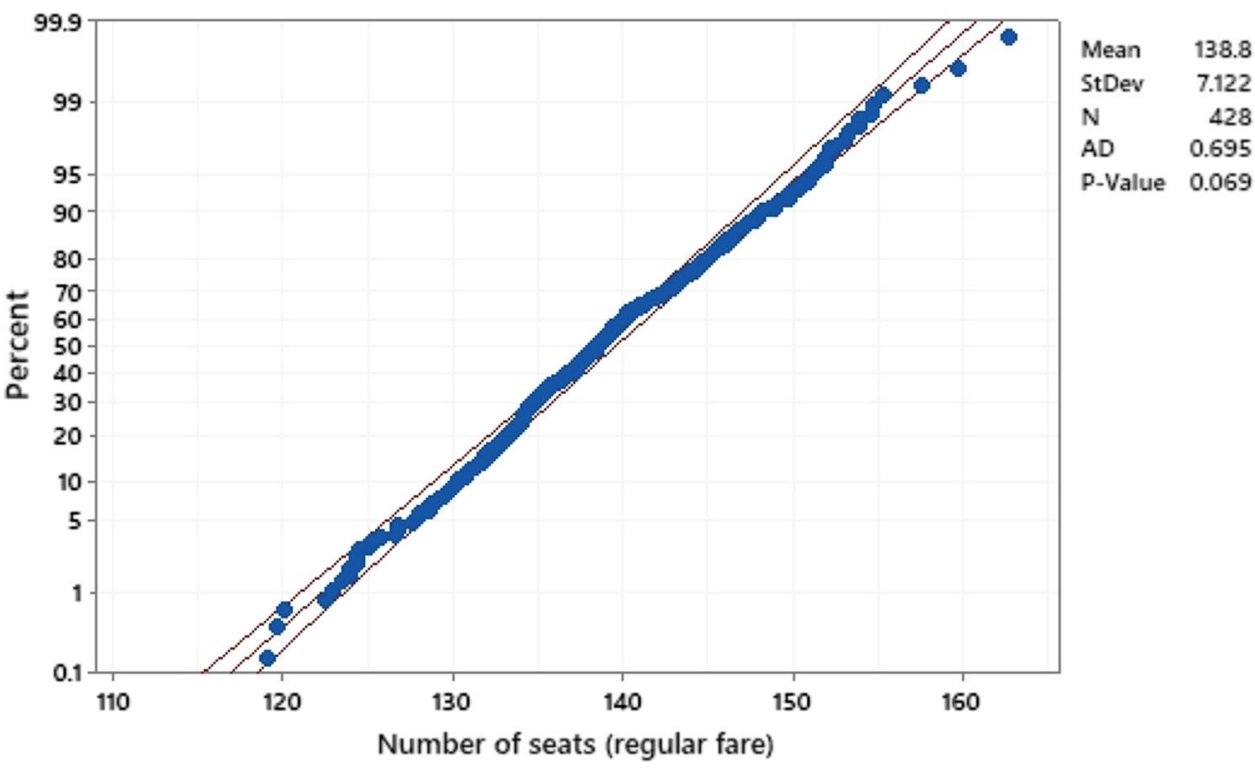


Table 1 Optimal number of seats at different discounted prices

\begin{tabular}{llll}
\hline & \multicolumn{2}{l}{$p_{\mathrm{d}}(\mathrm{AED})$} & \\
\cline { 2 - 4 } & 1023 & 525 & 25 \\
\hline $\begin{array}{l}\text { Discount ratio } \\
\begin{array}{l}\text { Optimal number of seats } \\
\text { (for regular price) }\end{array}\end{array}$ & $0 \%$ & $48.68 \%$ & $97.56 \%$ \\
& 118 & 139 & 153 \\
\hline
\end{tabular}

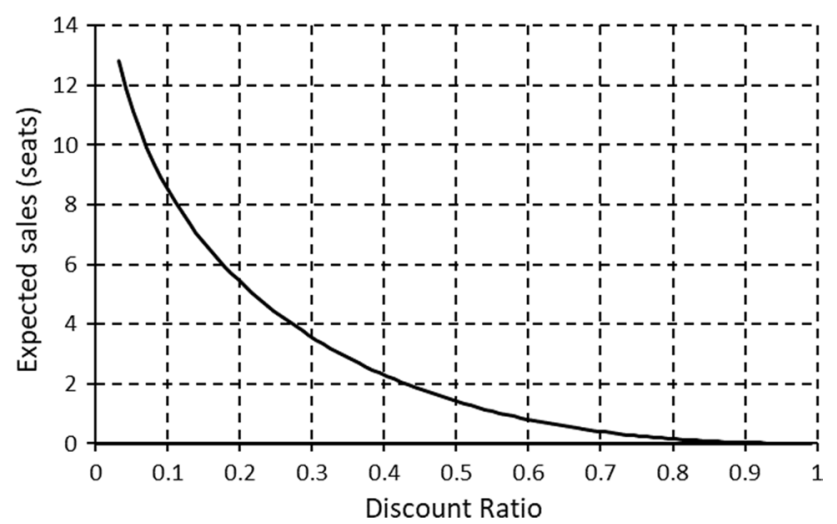

Fig. 10 Effect of discount ratio on the expected sales

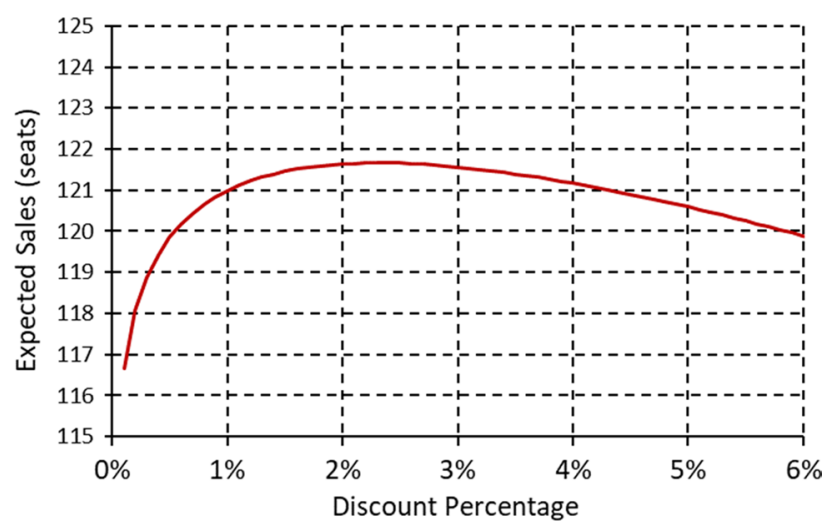

Fig. 11 Expected sales vs. discount ratio

For the same instance at a regular price of 1023AED, a mean of 138.8 and a standard deviation of 7.122 , the resulting lost sales will decline as a function of the discount ratio as shown in Fig. 10. Note that, as the discount ratio increases, the expected lost sales will decrease owed to the decrease in the mean and standard deviation.

From the graph in Fig. 10, we can conclude that whenever the discounted percentage is increasing, in other words, the price of the ticket is decreasing; the optimal number of seats offered at regular fare should increase. Many reasons might be behind this behavior. One is that the demand is increasing

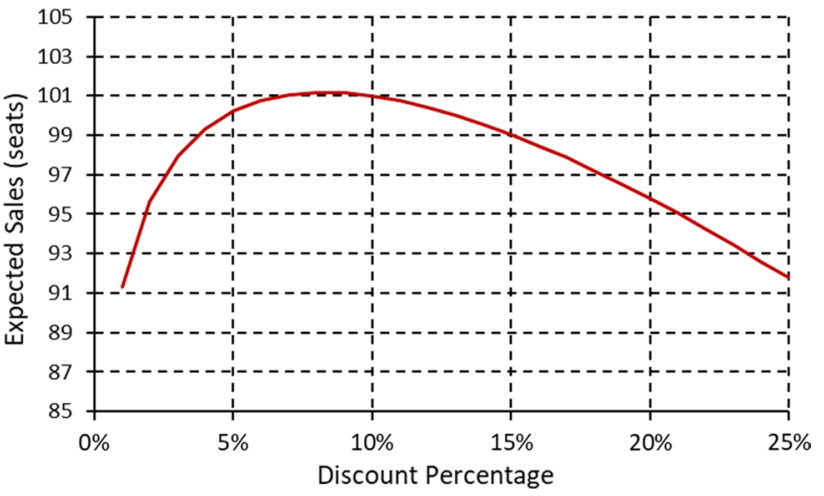

Fig. 12 Expected sales vs. discount ratio, $\mu=138.8$ and $\sigma=20$

from the perspective of the customer, so it is more profitable to reserve seats for the regular price.

For the sake of additional sensitivity analysis of flight no. G9105, we will fix $p_{\mathrm{r}}$ to $1023 \mathrm{AED}$ and test other input values as follows:

For the same actual mean and standard deviation $(\mu 1=138.8, \sigma 1=7.122)$. By sketching the sales vs. the discount ratio, we get the results in Fig. 11. The maximum expected sales appear to be equal to $121.66 \approx 122$ seats at a discount ratio of $2.3 \%$. Accordingly, the best discounted price equals $999.47 \mathrm{AED}$ and it is offered for only 46 seats, while the remaining seats are offered at a regular price of 1023 AED.

Consequently, we may conclude that the discounted price of 768 AED that is set by Air Arabia is not the best in terms of maximizing the sales. For the purpose of sensitivity analysis, we reduce the mean to $\mu=120$ seats while keeping the same standard deviation of $\sigma=7.122$. It can be found that the highest expected sale equals to103, which is achievable at a discount of $2.8 \%$ for only 64.6 discounted seats. In this case $p_{\mathrm{d}}$ is 994.35 AED.

Similarly, by considering a mean of 138.8 and a standard deviation of 20, an expected sale of 101.1754901 at almost $8 \%$ discount, for 66 discounted seats. The discounted price is $(1-0.08) \times 1023=941 \mathrm{AED}$. The result of this instance is shown in Fig. 12, which shows that higher standard deviations result in less sales.

In our next experimental results, we consider the period of 19/Nov/2020 to 10/April/2021 for the same flight, which was harshly hit by the COVID-19 pandemic. In this period, the civil aviation authority in UAE decided to operate Airbus of 186 seats with only 95 seats, although some literature studies suggested 106 seats (Majumder, 2020).

The collected data for this period show that the average demand was 75.05 seats and the associated standard deviation was 2.35 seats. Figure 13 shows the probability plot, which does not provide enough evidence to reject the normality assumption of the data. 
Fig. 13 Normality test of the collected data for the period of 19/Nov/2020 to 10/April/2021

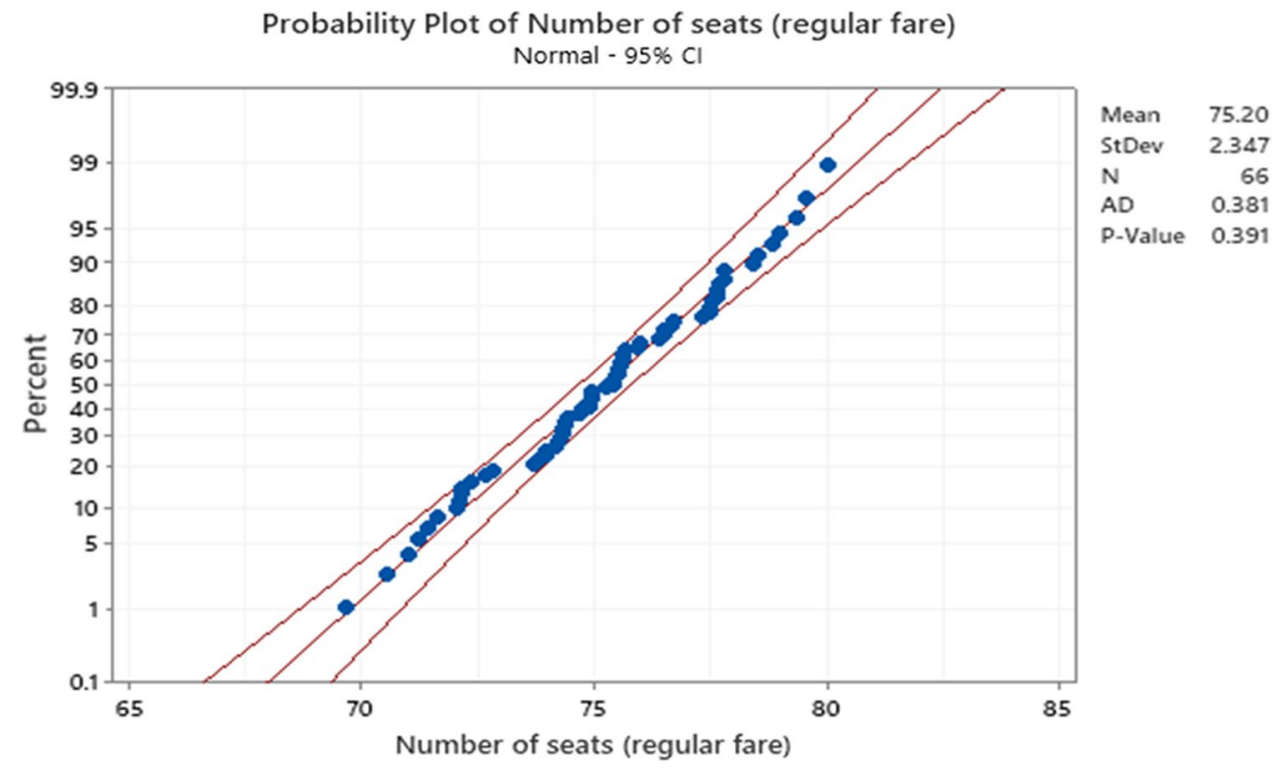

Table 2 Optimal number of seats at different discounted prices

\begin{tabular}{llll}
\hline & $p_{\mathrm{d}}(\mathrm{AED})$ & & \\
\cline { 2 - 4 } & 1023 & 525 & 25 \\
\hline Discount ratio & $0 \%$ & $48.68 \%$ & $97.56 \%$ \\
$\begin{array}{l}\text { Optimal number of seats } \\
\text { (for regular price) }\end{array}$ & 68.269 & 74.972 & 79.679 \\
\hline
\end{tabular}

Table 2 shows some calculated optimal seat allocation for different discounted prices. Of note, at zero discount, the optimal number of seats is 68 . This number will increase as the discount ratio increases to avoid any increase in the overage and underage costs.
Table 3 shows the expected sales, the optimal seats, and the best discount ratio for different means and standard deviations along with the actual values in the first record. The table shows that higher mean entails less optimal seats allocated for the regular fare, while higher demand standard deviation requires higher number of allocated seats for the same fare. Clearly, higher fill rates are observed for high means with low standard deviations, which come in line with the expectations when the risk is low (i.e., low $\sigma_{1}$ ). This also applies for the expected sales that can be found at uppermost values when the mean is high and the standard deviation is low.
Table 3 Optimal resutls for different means and standard devations

\begin{tabular}{lllllll}
\hline$\#$ & $\mu_{1}$ & $\sigma_{1}$ & $\begin{array}{l}\text { Expected sales } \\
\text { (seats) }\end{array}$ & Optimal seats & $\begin{array}{l}\text { Best discount } \\
\text { ratio }\end{array}$ & Fill rate \\
\hline 1 & 90 & 2.347 & 83.6868 & 11.3 & $1 \%$ & 0.93 \\
2 & 60 & 2.347 & 54.0594 & 40.9 & $2 \%$ & 0.90 \\
3 & 75.2 & 10 & 55.9237 & 38.7 & $8 \%$ & 0.74 \\
4 & 75.2 & 0.05 & 74.3327 & 20.7 & $1 \%$ & 0.99 \\
5 & 90 & 10 & 69.7423 & 25.0 & $6 \%$ & 0.77 \\
6 & 60 & 0.05 & 59.2847 & 35.7 & $1 \%$ & 0.99 \\
7 & 90 & 0.05 & 88.9847 & 6.0 & $1 \%$ & 0.99 \\
8 & 60 & 10 & 42.0399 & 52.5 & $10 \%$ & 0.70 \\
\hline
\end{tabular}




\section{Implications}

Although this study offers practical insights to managers and decision makers for managing flight seats and ticket prices, some implications may arise upon implementation. This study will help airlines manage and predict their overall profits by adequate fare management and seat allocation; however, this is possible under an assumption like linear multiplicative demand and standard deviation. Therefore, validation of the model becomes important for the selected flight leg. Some flights may not necessarily follow such multiplicative demand pattern. Moreover, the model tends to maximize the sales but not the profit, although maximizing the sales implies maximizing the profit in a way or another; however, the goal of this article is to increase the size of sales. Not only the multiplicative demand assumption, but also the discounted seats are assumed to be sold out at the end of the season. While this is a reasonable assumption as we seek to find the best price, however, the discounted prices have to be low enough to attract the travelers. Lastly, the model addresses two classes of seats, as more complicated models may be required for more seat classes. Overall, this study is expected to improve the efficiency, effectiveness, and market share by proper demand management and offering optimal and competitive fares of different classes to attract more passengers.

\section{Conclusion}

Practice in airline industry reveals that seat inventory control and, therefore, revenue management are more reliant on human judgment, which lacks systematic handling of randomness in inputs. This is attributed to the fact that managers are not in favor of complicated models found in the literature. To present a simple yet capable model, this research addresses air ticket pricing and demand management in a comprehensible approach. The study employs a new multiplicative demand model along with newsvendor approach to maximize the sales. Here, two seat classes were taken into account: regular fare seats and discounted fare seats. In this model, early bird customers will get the benefits of discounted price, while late customers will buy at a regular price. The objective was to classify the available seats into these two categories and to estimate the best prices that will maximize the sales. To do so, the airline has to determine the prices and quantities of the seats, which were addressed via fitting the relationship between the sold quantities and the discount ratio, and then constructing a decision problem that should be handled by airlines using the newsvendor approach.
It was found that an airline can maximize the sales by managing the prices and the number of seats offered for every class. The proposed model suggests the optimal number of seats and maximizes the sales of the different seat offerings. A case study from a real airline carrier has been tested for validation; it revealed the possibility of increasing the sales via pricing and offered quantities. The proposed study highlights the key characteristics of price and demand management of airlines that help improve the overall airline performance. It presents a simple pricing and quantification formulas that can be put in practice without having to dig deep in complicated models.

Like any other model, this study has some limitations, which may provide a room for future research opportunities. First, only economy class was considered; therefore, other fare classes such as business and first class may be considered for future research. Second, some limitations may come from the assumption of sale run out of discounted seats, which may not be the case in some circumstances. Lastly, while the model addresses stable randomness in demand, this may not be the case in different seasons, which may demonstrate different demand distributions. Finally, airlines may utilize the suggested approach to reduce human judgment in ticket pricing, control their price offers to meet sales targets, and enhance profitability.

\section{References}

Alrawabdeh, W. 2021. Seasonal balancing of revenue and demand in hotel industry: The case of Dubai City. J Revenue Pricing Manag. https://doi.org/10.1057/s41272-021-00290-6.

Alves, U., and M. Caetano. 2016. Analysis of ticket price in the airline industry from the perspective of operating costs, supply and demand. Aviation in Focus 7 (2): 21-28. https://doi.org/10.15448/ 2179-703X.2016.2.23185.

Andrés Martínez, M., J. Alfaro Navarro, and J. Trinquecoste. 2017. The effect of destination type and travel period on the behavior of the price of airline tickets. Research in Transportation Economics 62: 37-43. https://doi.org/10.1016/j.retrec.2017.03.003.

Belobaba, P.P. 1987. Airline yield management an overview of seat inventory control. Transportation Science 21: 63-73.

Bitran, G., and R. Caldentey. 2003. An overview of pricing models for revenue management. Manufacturing and Service Operations Management 5 (2003): 203-229.

Chen, Y., and V. Farias. 2018. Robust dynamic pricing with strategic customers. Mathematics of Operations Research 43 (4): 1051-1404.

Cizaire, C., and P. Belobaba. 2013. Joint optimization of airline pricing and fare class seat allocation. Journal of Revenue and Pricing Management 12: 83-93.

Dalalah, Doraid, Udechukwu Ojiako, and Maxwell Chipulu. 2020. Voluntary overbooking in commercial airline reservations. Journal of Air Transport Management 86: 101835.

Karlin, S., and C. Carr. 1962. Prices and optimal inventory policy. In Studies in applied probability and management science, ed. K. 
Arrows, S. Karlin, and H. Scarf. Stanford: Stanford University Press.

Ko, Y. 2019. The airfare pricing and seat allocation problem in fullservice carriers and subsidiary low-cost carriers. Journal of Air Transport Management 75: 92-102. https://doi.org/10.1016/j.jairt raman.2018.12.003.

Lan, Y., M. Ball, Zhang I. Karaesmen, and G. Liu. 2015. Analysis of seat allocation and overbooking decisions with hybrid information. European Journal of Operational Research 240 (2): 493504. https://doi.org/10.1016/j.ejor.2014.07.021.

Liu, B., Y. Tan, and H. Zhou. 2016. A Bayesian predictor of airline class seats based on multinomial event model. IEEE International Conference on Big Data (Big Data), Washington, DC, pp. 17871791, https://doi.org/10.1109/BigData.2016.7840795.

Mookherjee, R., and T.L. Friesz. 2008. Pricing, allocation, and overbooking in dynamic service network competition when demand is uncertain. Production and Operations Management 17: 455-474.

Pertiwi, L., and Wagiono, and Simanullang, H. 2015. Stochastic model for airline revenue management. International Journal of Science and Research (IJSR) 4 (9): 1318-1321.

Petruzzi, Nicholas C., and Maqbool Dada. 1999. Pricing and the newsvendor problem: A review with extensions. Operations Research 47 (2): 183-194. https://doi.org/10.1287/opre.47.2.183.

Rico Merkert, Tony Webber. 2018. How to manage seasonality in service industries-The case of price and seat factor management in airlines. Journal of Air Transport Management 72
Sakkakom, Maneenop, Suntichai Kotcharin. 2020.The impacts of COVID-19 on the global airline industry: An event study approach, Journal of Air Transport Management 101920

Tesfay, Y. 2016. Modified panel data regression model and its applications to the airline industry: Modeling the load factor of Europe North and Europe Mid Atlantic flights. Journal of Traffic and Transportation Engineering 3 (4): 283-295. https://doi.org/10. 1016/j.jtte.2016.01.006.

Wang, Y. 2016. Dynamic pricing considering strategic customers. International Conference on Logistics, Informatics and Service Sciences (LISS), Sydney, NSW, pp. 1-5. https://doi.org/10.1109/ LISS.2016.7854471.

Whitin, T.M. 1955. Inventory control and price theory. Management Science 2 (1): 61-68.

Zhao, X., D. Atkins, M. Hu, and W. Zhang. 2017. Revenue management under joint pricing and capacity allocation competition. European Journal of Operational Research 257: 957-970.

Publisher's Note Springer Nature remains neutral with regard to jurisdictional claims in published maps and institutional affiliations. 